\title{
Complexity of Pain Management Among Patients with Nociceptive or Neuropathic Neck, Back, or Osteoarthritis Diagnoses
}

\author{
Chris M. Kozma, PhD; David A. Provenzano, MD; Terra L. Slaton, MS; \\ Aarti A. Patel, PharmD, MBA; and Carmela J. Benson, MS
}

\begin{abstract}
BACKGROUND: Approaches to pain management are diverse, requiring prescribers to evaluate an array of clinical issues and potential solutions. In addition to the difficult task of selecting a treatment option, pain treatment may be further complicated by multiple prescribers, multiple medications, and multiple mechanisms of pain origination.

OBJECTIVE: To describe patient demographics (e.g., age, gender); comorbidities; office visits (e.g., physician, chiropractor, physical therapy, psychiatry, allergist); number of different prescribers overall prescription use; pain medications as classified by the World Health Organization's (WHO) pain ladder; adjuvant medications; nonpharmacologic procedures; and potential drug interactions in a broad sample of patients with nociceptive or neuropathic neck or back diagnoses, or osteoarthritis diagnoses, in a commercial population.
\end{abstract}

METHODS: This claims-data analysis used a cross-sectional cohort comparison with a fixed 2-year observation period from September 1, 2006, to August 31, 2008, for patients in the PharMetrics national managed care database. The assigned cohorts were neuropathic-related neck/back diagnoses (NEUR0); neuropathic and nociceptive neck/back diagnoses (NEURO/ $\mathrm{NOCI}$; nociceptive neck/back diagnoses without a neuropathic-related diagnosis ( $\mathrm{NOCl);} \mathrm{and} \mathrm{only} \mathrm{osteoarthritis} \mathrm{(OA)} \mathrm{diagnoses.} \mathrm{All} \mathrm{analyses}$ were conducted by cohort. The analysis included the following patientdescriptive variables: patient demographics, comorbidities, office visits, most frequent medical providers and number of different prescribers, all medications, pain medications as classified by the WHO pain ladder, adjuvant medications, adjuvant procedures and potential drug interactions. The goal for selecting these variables was to describe a range of data that might provide insight into the complexity of pain management decisions faced by clinicians.

RESULTS: The study included 85,014 patients, classified as NEURO $(n=2,375)$, NEURO/NOCI $(n=37,019), N O C I(n=39,496)$, and OA $(n=6,124)$. The most frequently occurring comorbidities (observed in $>40 \%$ of patients) included cardiovascular and neuropathic pain conditions. Considering all types of medication claims observed among all cohorts, the overall mean prescription claim count for the 2-year observation period was 57.9 claims (standard deviation 56.2). Weak opioids (WHO pain relief ladder rung 2) accounted for the majority of pain medication claims across all cohorts. Across cohorts, $25.7 \%$ of patients had 10 or more days of overlapping drug availability (for inducers or inhibitors of the cytochrome P450 system concomitantly), a measure of potential for drug interactions.

CONCLUSIONS: Choosing the appropriate pain treatment involves assessing currently used medications for existing illnesses and deciding on the appropriate types of pain medications. However, potentially serious drug-drug interactions are a consequence of multiple drug use, and such a potential requires thoughtful consideration by those involved in patient care.

J Manag Care Pharm. 2014;20(5):455-66

Copyright $\odot 2014$, Academy of Managed Care Pharmacy. All rights reserved.

\section{What is already known about this subject}

- Pain relief is one of the leading reasons for health-seeking behavior. Pain may be localized or general and may arise from various etiologies, including joint and arthritic injury, herpes zoster, multiple sclerosis, spinal injury, and pain-related conditions such as diabetic polyneuropathy and fibromyalgia.

- Pain is caused by different pathophysiological mechanisms, including neuropathic, nociceptive, and a mix of neuropathic and nociceptive mechanisms. Neuropathic pain is caused by a lesion or dysfunction of the peripheral or central nervous system. Nociceptive pain is associated with the stimulation of nociceptive nerve receptors that transmit signals to the central nervous system. Neuropathic pain is believed to be the most challenging to treat.

- Patients are treated with a variety of modalities to control pain, including physical therapy, psychological therapy, acupuncture, acupressure, and interventional pain procedures that include spinal cord stimulation, biofeedback, transdermal electric stimulation, complementary and alternative medicine, and pharmacological treatment.

\section{What this study adds}

- To our knowledge, this is the first study that has assessed a large population of mixed sources of pain in order to understand the characteristics of patient populations that might contribute to increased risks for complications when making medication prescribing decisions

- This analysis highlights a breadth of pain management variables evaluated in a single population of patients, as opposed to analyses that have examined single variables.

- This study documents treatments for a range of patients with neck and back pain diagnoses for whom clinicians might have to make pain management decisions.

\footnotetext{
A pproaches to pain management are diverse, requiring prescribers to evaluate an array of clinical issues 1 and potential solutions. Treatment options including lifestyle changes, medications, cognitive and physical therapy, surgery, and alternative medicine are weighed in consideration of other patient factors such as age and comorbid conditions. In addition to the difficult task of selecting a treatment option, pain treatment may be further complicated by the use of multiple classes of medications ${ }^{1-3}$ and multiple mechanisms of pain origination. $^{4}$
} 
In addition to complaints of pain, patients often present with other multiple coexisting chronic diseases. ${ }^{5-8}$ According to the Centers for Disease Control and Prevention, $47 \%$ of U.S. adults aged 55 or greater have 2 or more chronic conditions (e.g., arthritis, asthma, cancer, cardiovascular disease, chronic obstructive pulmonary disease, and diabetes). ${ }^{9}$ These diseases require chronic treatment, often with multiple medications. Thus, pain treatment is often concurrent with chronic disease treatment in a large number of patients.

There are few published studies that describe the complexity of pain management. This analysis attempts to provide an in-depth description of the potential complexities associated with pain management in terms of patient characteristics, physician involvement, medication variety, and other treatment services used in a large cohort of patients receiving treatment for chronic or acute pain. The goal of the analysis was to raise awareness of the complexity of treating pain with the focus specifically on medications, since medications are a mainstay of pain treatment. Understanding the characteristics of patient populations that might contribute to increased risks for complexity may signal areas that need attention when making medication-prescribing decisions. Factors that may require specific consideration by clinicians when prescribing medications are highlighted.

\section{Methods}

\section{Data Source}

Patients with commercial coverage were selected from the PharMetrics (Watertown, MA) national managed care database. The PharMetrics database is an anonymous patient-centric database that represents more than 60 million enrollees from more than 95 health plans and provides comprehensive medical and prescription claims data. The database is a de-identified, HIPAA (Health Insurance Portability and Accountability Act of 1996) compliant database and, as such, no institutional review board approval was necessary.

\section{Study Design}

This analysis used a cohort comparison with a fixed 2-year observation period from September 1, 2006, to August 31, 2008 , during which all patients were required to have continuous insurance coverage. To ensure that patients had a diagnosis of interest at the start of the period for which data were reported, at least 1 diagnosis of interest was required in the prior 1-year preperiod (September 1, 2005-August 31, 2006).

\section{Analysis Population}

The strategy for patient selection was to obtain a sample with neck and back diagnoses in which the magnitude of variables affecting pain management complexity might be inferred. The selection criteria were designed to identify patients who had any moderate pain therapy exposure, for whom there would be complete data, and in whom a common alternative reason for pain medication use (i.e., cancer) was removed. The goal was to identify a wide range of patients of the type that might be seen in clinical practice, who had neuropathic or nociceptive neck or back diagnoses.

Patients were included in this analysis if they met all of the following criteria: (a) had continuous insurance eligibility between September 1, 2006, and August 31, 2008; (b) were at least 18 and no more than 63 years of age as of 2006 (to exclude patients who may have switched to Medicare coverage during the observation period); (c) had at least 2 claims (any analysis diagnosis) separated by at least 90 days for an analysis inclusion diagnosis between September 1, 2005, and August 31, 2006 , and at least 1 during the observation period (September 1, 2006-August 31, 2008); and (d) had at least 1 oral opioid prescription claim during the observation period. The opioid restriction was applied to provide some minimal evidence of pain medication use

Patients were excluded from the analysis if they met any of the following exclusion criteria: (a) had 1 or more claims indicating a stay in a long-term care or skilled nursing facility (because of concerns about the completeness of their claims data); (b) had a diagnosis for history of alcohol and/or drug abuse; (c) had a pregnancy or pregnancy-related claim during the observation period; (d) had a surgical procedure involving the spine or intervertebral disc prior to the observation period; (e) had a diagnosed malignancy, with the exception of nonmelanoma skin cancers, during or prior to the observation period; (f) had noncommercial coverage; or ( $g$ ) had invalid or missing data for key analysis variables.

Patients meeting the analysis inclusion and exclusion criteria were assigned to neuropathic and nociceptive neck and back and osteoarthritis cohorts based on the presence of diagnosis codes for 1 of the selected conditions, based on the International Classification of Diseases, Ninth Revision, Clinical Modification (ICD-9-CM; Table 1). The assigned cohorts were neuropathic-related neck/back diagnoses (NEURO); neuropathic and nociceptive neck/back diagnoses (NEURO/NOCI); nociceptive neck/back diagnoses without a neuropathic-related diagnosis (NOCI); and only osteoarthritis (OA) diagnoses. NOCI, NEURO, and NEURO/NOCI were assigned without regard to coexisting OA diagnoses. See Figure 1 for sample identification.

\section{Statistical Analysis}

Categorical variables were summarized using frequencies and percentages. Continuous measures were summarized with means, standard deviations, minimums, maximums, and medians. Comparisons between cohorts were conducted with analysis of variance for continuous measures and chi-square tests for categorical variables. While statistical tests were conducted, we note that there are large and disparate sample 
Complexity of Pain Management Among Patients with Nociceptive or Neuropathic Neck, Back, or Osteoarthritis Diagnoses

\section{TABLE $1 \longdiv { \text { Description of Coding } }$}

\begin{tabular}{|c|c|c|}
\hline Type of Pain & Description & Codes \\
\hline \multirow[t]{4}{*}{ NEURO } & Low back pain/disorders with radicular leg pain & $723.4 X, 724.3 X, 724.4 X, 729.2 X$ \\
\hline & Neck pain with neuropathic involvement & $721.1 \mathrm{X}, 722.0 \mathrm{X}, 723.0 \mathrm{X}$ \\
\hline & Back or neck with neuropathic involvement, predominately back & $721.4 \mathrm{X}, 722.1 \mathrm{X}, 724.0 \mathrm{X}$ \\
\hline & Back or neck with neuropathic involvement, predominately neck & $721.91,722.2 \mathrm{X}, 722.7 \mathrm{X}$ \\
\hline \multirow{4}{*}{$\begin{array}{l}\text { NEURO/ } \\
\text { NOCIa }\end{array}$} & Low back pain/disorders with radicular leg pain & 723.4X, 724.3X, 724.4X, 729.2X, and any diagnosis below \\
\hline & Neck pain with neuropathic involvement & 721.1X, 722.0X, 723.0X, and any diagnosis below \\
\hline & Back or neck with neuropathic involvement, predominately back & 721.4X, 722.1X, 724.0X, and any diagnosis below \\
\hline & Back or neck with neuropathic involvement, predominately neck & $721.91,722.2 \mathrm{X}, 722.7 \mathrm{X}$, and any diagnosis below \\
\hline \multirow[t]{4}{*}{$\mathrm{NOCI}$} & Back without radicular leg pain & $\begin{array}{l}\text { 724.2X, 724.5X, 724.6X, 724.9X, 721.2X, 721.3X, 722.5X, 724.1X, } \\
\text { 724.7X, 724.8X, 739.2X, 739.3X, 739.4X, 846.0X, 846.1X, 846.8X, } \\
\text { 846.9X, 847.1X, 847.2X, 847.3X, 847.4X, 847.9X, 722.3X, 846.3X }\end{array}$ \\
\hline & Neck pain without neuropathic involvement & $\begin{array}{l}\text { 721.0X, 723.1X, 723.2X, 723.3X, 723.5X, 723.6X, 723.7X, 723.8X, } \\
\text { 723.9X, 847.0X }\end{array}$ \\
\hline & Back or neck, predominately back without neuropathic involvement & 720.0X, 720.1X, 720.2X, 721.5X, 721.8X, 720.8X \\
\hline & Back or neck, predominately neck without neuropathic involvement & $\begin{array}{l}\text { 720.9X, 721.6X, 721.7X, 721.90, 722.4X, 722.6X, 738.4X, 739.1X, } \\
846.2 \mathrm{X}\end{array}$ \\
\hline $\mathrm{OA}^{\mathrm{b}}$ & Osteoarthritis cohort total & $715 . \mathrm{XX}$ \\
\hline
\end{tabular}

aThe NEURO/NOCI pain cohort consisted of patients with 1 or more diagnoses for neuropathic pain and at least 1 additional diagnosis for neck/back pain without neuropathic involvement during the observation period.

${ }^{b}$ Any cohort may or may not have had an osteoarthritis diagnosis. The osteoarthritis cohort had no diagnosis from any other cohort.

NEURO=neuropathic-related neck/back diagnoses; NEURO/NOCI=neuropathic and nociceptive neck/back diagnoses; NOCI=nociceptive neck/back diagnoses;

$O A=$ osteoarthritis

sizes. In many cases, trivial differences may be statistically significant. The interpretation should rely on differences that are of clinical significance. Given the large number of comparisons, only general comments are made regarding statistical significance. No adjustments were made for multiplicity. SAS/ STAT software for Windows version 9.2 (SAS Institute Inc., Cary, NC) was used for all analyses.

\section{Variable Descriptions}

The analysis included the following variables: patient demographics (e.g., age, gender); comorbidities; office visits (e.g., physician, chiropractor, physical therapy, psychiatry, allergist); the percentage of patients with visits to medical providers by specialty and number of different prescribers; the mean number of prescription claims; pain medications as classified by the World Health Organization (WHO) pain ladder; adjuvant medications; adjuvant procedures; and potential drug interactions. All analyses were conducted by cohort. Operational definitions of the key variables are presented in the following sections.

Comorbidities of interest and specific codes are presented in Appendix A (available in online article). Comorbidities were identified from a published article using the ICD-9-CM diagnosis codes and refined based on an analysis by Gore et al. (2011). ${ }^{10}$ The percentage of patients with at least 1 claim during the 2-year observation period with each of the comorbidities was identified.

Office visit counts for the observation period were calculated for the overall group and for each cohort using claims data. The observation period was a fixed 2-year observation period from September 1, 2006, to August 31, 2008.

Most frequently appearing medical providers during the observation period were identified using the Standard Provider field included in the outpatient claims database. Standard Provider is a field provided by the data vendor that describes the provider's specialty. Each uniquely identified provider per patient per date was counted as 1 occurrence. In addition to this more general assessment, prescribing specialties were identified qualitatively from the list of Standard Provider types assigned in order to provide a count from the subset of provider types who regularly prescribe chronic medications to the patients in our analysis. Counts for the number of patients with visits to these providers were provided. Mean prescription claims counts for the entire observation period were calculated and grouped into categories using National Drug Codes. These counts included all of the prescription claims, including new or refill medications. The claims were divided into categories of all prescriptions, pain-related, adjuvant, and nonpain-related prescriptions. Claims count and categories were assessed for each cohort.

The assessment of pain medication was based on the WHO pain ladder. The pain ladder has 3 steps representing mild, moderate, and severe pain. For step 1 (mild pain), nonopioid medications with or without adjuvant analgesic therapy are recommended. Typically, the drugs used at this step are acetaminophen or nonsteroidal anti-inflammatory medications (NSAIDs; e.g., aspirin, ibuprofen, diclofenac). Step 2 on the 


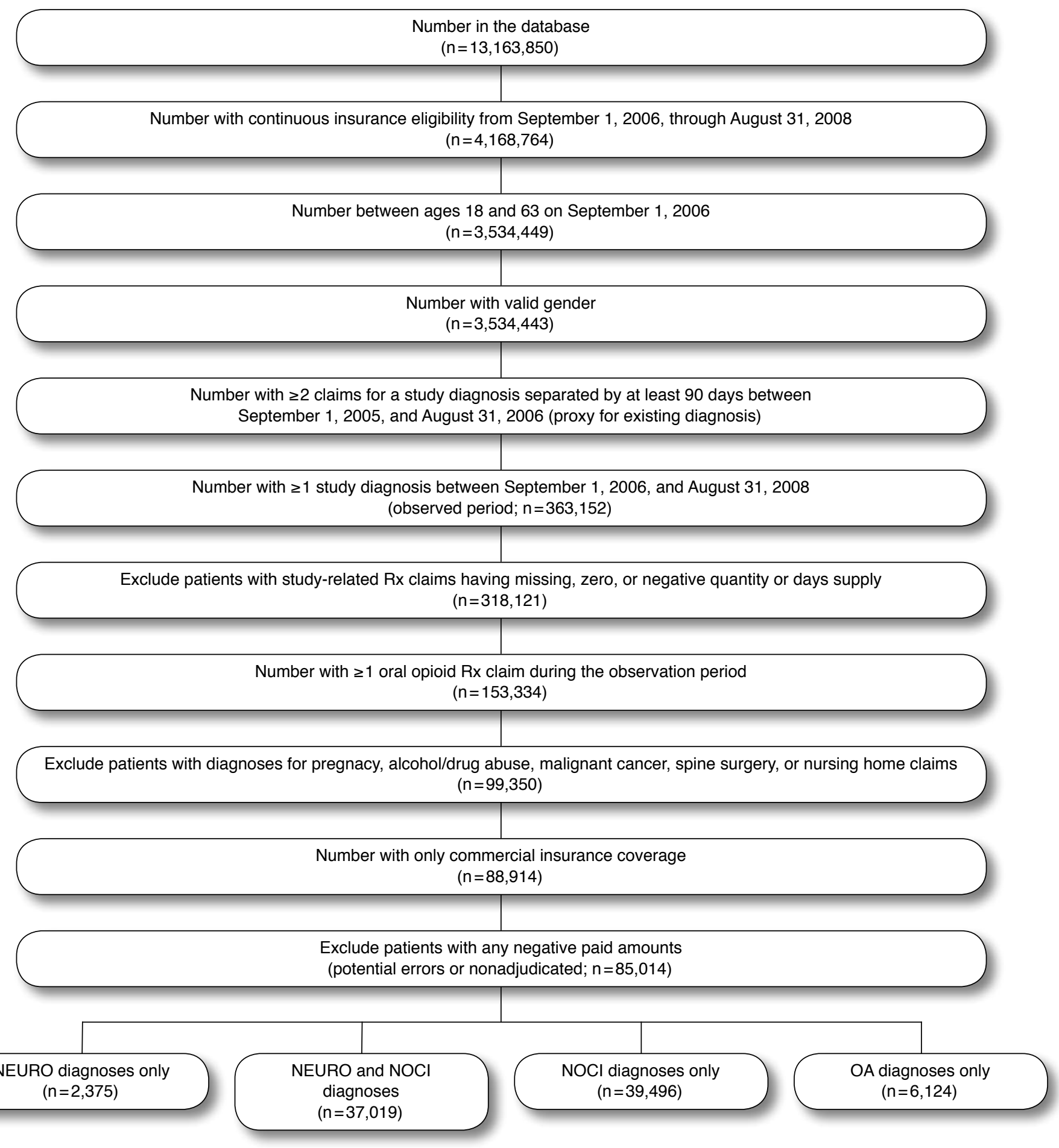

NEURO = neuropathic-related neck/back diagnoses; NEURO/NOCI = neuropathic and nociceptive neck/back diagnoses; NOCI = nociceptive neck/back diagnoses; $O A=$ osteoarthritis; $R x=$ prescription 


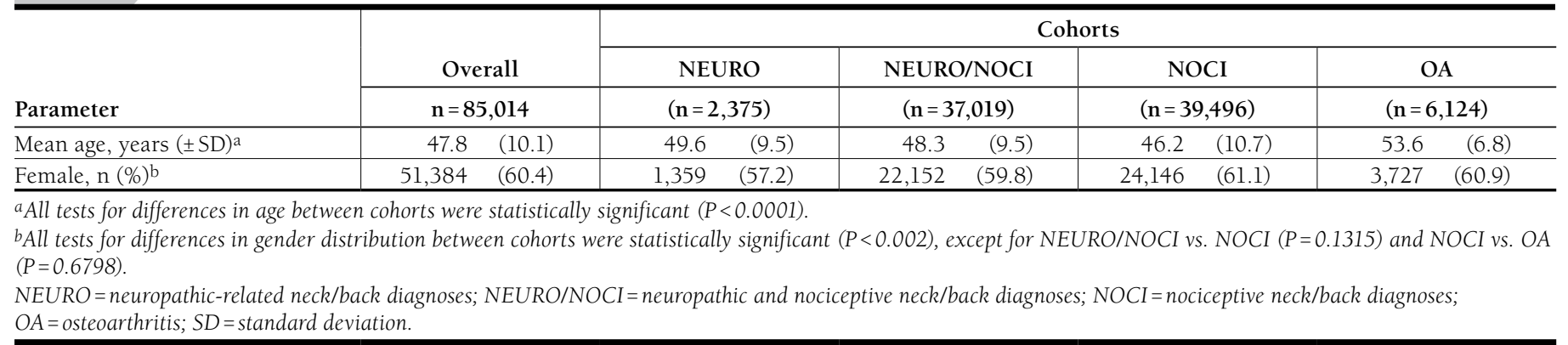

ladder (moderate pain) adds the use of a weak opioid (e.g., tramadol, codeine, dihydrocodeine). The third rung (severe pain) adds the use of strong opioids (e.g., morphine, fentanyl, buprenorphine, oxycodone, hydromorphone). The medications included on the rungs of the WHO pain relief ladder are shown in Appendix B (available in online article). Medication availability was defined as the percentage of days where a patient theoretically had access to the drug based on the dispensing dates and days supply. Days of availability for pain ladder classes were categorized into $>0 \%$ to $<30 \%, 30 \%$ to $<80 \%$, and $\geq 80 \%$.

Adjuvant treatments may be used at any step on the ladder and include antidepressants, anticonvulsants, steroids, muscle relaxants, exercise, psychological support, temperature therapy, physical therapy, hydrotherapy, and acupuncture. Adjuvant pain medications were categorized using the therapeutic classes and then were refined based on a published list. ${ }^{11}$ The therapeutic class approach is broader than just the specific pain-related adjuvant treatments; however, use of any drug in the class may affect pain treatment decisions.

Drug interaction potential was also evaluated. Potential drug interactions were defined based on the interaction within the cytochrome P450 system. Pain medications were evaluated both as substrates on which other drugs could act and as inhibitors and inducers that act on other drugs as substrates. Pain medications were assessed for overlapping availability (i.e., based on dispensing dates and days supplies) for a minimum of 10 days based on dispensing dates and days supply of medication (a proxy for concomitant use).

Adjuvant therapies (e.g., chiropractic therapy, physical therapy) also are used to treat pain. Adjuvant therapies were identified using medical codes that are frequently associated with the treatment of pain. These procedures were included to provide a comprehensive view of how pain is treated.

\section{Results}

\section{Patient Demographics and Comorbidities}

The analysis included 85,014 patients, of which 2,375 were classified as NEURO; 37,019 were NEURO/NOCI; 39,496 were NOCI; and 6,124 were OA. The mean age of the overall sample was 47.8 years, and females comprised $60.4 \%$ (Table 2). The most frequently occurring comorbidities (observed in $>40 \%$ of patients) included cardiovascular and neuropathic pain conditions (in the NEURO and NEURO/NOCI groups only; Table 3). Hypertension was the most commonly observed specific comorbidity, occurring in more than $60 \%$ of OA patients, followed by NEURO (46.9\%), NEURO/NOCI (43.6\%), and NOCI (35.2\%) patients.

Hyperlipidemia occurred in $59.5 \%$ of OA patients, followed by NEURO (51.6\%), NEURO/NOCI (48.9\%), and NOCI (41.6\%) patients. Depression was observed in $21.3 \%$ of NEURO/NOCI patients, followed by NOCI (18.4\%), OA (15.8\%), and NEURO (15.6\%) patients. Diabetes was observed in $22.4 \%$ of OA patients, followed by NEURO (19.8\%), NEURO/NOCI (15.4\%), and NOCI (11.7\%) patients. Sleep disturbance was observed in $20.0 \%$ of the NEURO/NOCI cohort, followed by OA (18.9\%), NEURO (16.6\%), and NOCI (16.6\%) cohorts. Thyroid disorder was observed in $15 \%$ to $19 \%$ of the cohorts. If a significant omnibus test $(P<0.05)$ was found using ANOVA, then pairwise statistical tests were conducted. The results of these tests indicated that differences equal to or larger than the following magnitudes were statistically significant $(P<0.05$ or less): NEURO versus NEURO/NOCI 1.5\%; NEURO versus NOCI 0.5\%; NEURO versus OA 1.6\%; NEURO/NOCI versus NOCI $0.2 \%$; $\mathrm{NEURO} / \mathrm{NOCI}$ versus $\mathrm{OA} 0.5 \%$; and $\mathrm{NOCI}$ versus $\mathrm{OA} 0.5 \%$.

\section{Office Visits}

The mean number of office visits during the observation period for the overall population was 32.0 (standard deviation [SD] 27.9) visits (Table 4). The NEURO/NOCI cohort led the office visits with a mean of 38.1 visits (SD 31.3), followed by the NOCI, NEURO, and OA cohorts at 28.4 visits (SD 24.6), 25.1 visits (SD 23.6), and 20.8 visits (SD 18.3) during the 2-year observation period. All pairwise statistical tests were significant at $P<0.0001$.

\section{Medical Providers}

Overall visits to prescribing specialists indicate that general and family practice (GP/FP) and internal medicine (IM) physicians accounted for the highest percentage of patients with at least 1 visit during the 2-year analysis definition period, 


\section{TABLE 3 Patient Characteristics}

\begin{tabular}{|c|c|c|c|c|}
\hline \multirow[b]{3}{*}{ Comorbidity } & \multirow{2}{*}{$\begin{array}{l}\text { NEURO }^{a} \\
(n=2,375)\end{array}$} & \multirow{2}{*}{$\begin{array}{c}\text { NEURO/NOCI } \\
(\mathbf{n}=37,019)\end{array}$} & \multirow{2}{*}{$\begin{array}{c}\text { NOCI }^{\mathrm{a}} \\
(\mathrm{n}=39,496)\end{array}$} & \multirow{2}{*}{$\begin{array}{c}\mathrm{OA}^{\mathrm{a}} \\
(\mathrm{n}=6,124)\end{array}$} \\
\hline & & & & \\
\hline & $\%^{b}$ & $\%^{b}$ & $\%^{\mathrm{b}}$ & $\%^{b}$ \\
\hline Psychiatric conditions & 22.4 & 29.3 & 25.4 & 21.8 \\
\hline Depression & 15.6 & 21.3 & 18.4 & 15.8 \\
\hline Anxiety & 8.8 & 12.3 & 10.1 & 7.8 \\
\hline Bipolar disorder & 1.1 & 1.1 & 0.8 & 0.7 \\
\hline Generalized anxiety disorder & 3.2 & 4.1 & 3.2 & 2.7 \\
\hline Panic disorder & 1.3 & 1.9 & 1.3 & 1.0 \\
\hline Post-traumatic stress disorder & 0.5 & 0.9 & 0.8 & 0.6 \\
\hline Sleep distubances & 16.6 & 20.0 & 16.6 & 18.9 \\
\hline Insomnia/sleep disorders & 15.3 & 18.5 & 15.3 & 16.8 \\
\hline Sleep apnea & 8.3 & 8.8 & 7.2 & 9.9 \\
\hline Cardiovascular disorders & 65.6 & 62.7 & 53.7 & 77.8 \\
\hline Hypertension & 46.9 & 43.6 & 35.2 & 60.4 \\
\hline Hyperlipidemia & 51.6 & 48.9 & 41.6 & 59.5 \\
\hline Coronary heart disease & 11.0 & 9.4 & 6.4 & 11.5 \\
\hline Myocardial infarction & 1.5 & 1.4 & 1.0 & 1.6 \\
\hline Congestive heart failure & 2.3 & 1.5 & 1.1 & 2.4 \\
\hline Peripheral vascular disease & 3.5 & 2.8 & 1.4 & 3.1 \\
\hline Chronic obstructive pulmonary disease & 5.9 & 4.7 & 3.2 & 5.1 \\
\hline Chronic renal failure & 1.9 & 1.3 & 1.1 & 2.1 \\
\hline Diabetes & 19.8 & 15.4 & 11.7 & 22.4 \\
\hline Musculoskeletal pain conditions & 90.0 & 99.2 & 92.6 & 100.0 \\
\hline Rheumatism, excluding the back & 62.0 & 70.8 & 55.7 & 61.6 \\
\hline Arthritis and other arthropathies & 53.9 & 60.3 & 51.8 & 76.9 \\
\hline Back and neck pain, excluding low back pain & 23.3 & 81.2 & 63.1 & 0.2 \\
\hline Lumbago & 0.0 & 63.1 & 44.2 & 0.0 \\
\hline Low back pain & 27.7 & 57.7 & 16.0 & 0.2 \\
\hline Osteoarthritis & 33.8 & 32.5 & 25.8 & 100.0 \\
\hline Rheumatoid arthritis & 3.7 & 3.4 & 2.6 & 6.2 \\
\hline Neuropathic pain conditions & 71.1 & 77.5 & 11.0 & 10.9 \\
\hline Diabetic peripheral neuropathy & 0.7 & 0.7 & 0.5 & 0.4 \\
\hline Postherpetic neuropathy & 0.3 & 0.3 & 0.2 & 0.3 \\
\hline Other polyneuropathies & 11.4 & 12.5 & 5.8 & 4.8 \\
\hline Back and neck pain with neuropathic involvement & 52.3 & 65.7 & 0.0 & 0.0 \\
\hline Trigeminal neuralgia & 0.4 & 0.4 & 0.3 & 0.2 \\
\hline Carpal tunnel syndrome & 7.4 & 8.6 & 4.7 & 5.8 \\
\hline Causalgias & 3.6 & 3.3 & 1.2 & 1.2 \\
\hline Atypical facial pain & 0.4 & 0.5 & 0.3 & 0.3 \\
\hline Neuritis radiculitis, unspecified & 16.2 & 13.5 & 0.0 & 0.0 \\
\hline Phantom limb pain & 0.0 & 0.0 & 0.0 & 0.0 \\
\hline Autonomic neuropathies & 0.4 & 0.4 & 0.2 & 0.2 \\
\hline $\begin{array}{l}\text { aPairwise tests following a significant omnibus ANOVA ( } \\
(P<0.05 \text { and less): NEURO vs. NEURO/NOCI 1.5\%; NE } \\
\text { vS. OA 0.5\%. } \\
\text { bDenominators for means and percentages are the number } \\
\text { NEURO = neuropathic-related neck/back diagnoses; NEU } \\
O A=\text { osteoarthritis. }\end{array}$ & $\begin{array}{l}\text { at differences } \\
5 \% \text {; NEURO } \\
\text { ach cohort. Pa } \\
\text { athic and noc }\end{array}$ & $\begin{array}{l}\text { or larger than the fo } \\
5 \% \text {; NEURO/NOCI } \\
2 \text { be in more than } 1 r \\
\text { neck/back diagnoses }\end{array}$ & $\begin{array}{l}\text { magnitudes } w \\
\text { CI } 0.2 \% \text {; NEU } \\
\text { is table is organ } \\
=\text { nociceptiven }\end{array}$ & $\begin{array}{l}\text { ally significant } \\
\text { vs. OA } 0.5 \% \text {; NOC } \\
\text { ling to Gore et al. }{ }^{10} \\
\text { liagnoses; }\end{array}$ \\
\hline
\end{tabular}

at $39.8 \%$ and $16.9 \%$, respectively (Table 5 ). The NOCI group exhibited the highest percentage of patient visits to GP/FP physicians at $42.1 \%$, followed by the NEURO/NOCI (38.9\%), OA (33.1\%), and NEURO (32.2\%) groups. IM visits were highest in the OA group with $20.7 \%$ of patients having at least 1 visit. Other specialists such as orthopedic surgeons, cardiologists, and obstetrics/gynecology that were listed in the database are shown in the table. Nonsignificant pairwise differences are 


\section{TABLE 4 Mean Total Number of Office Visits Per Patient During the 2-Year Observation Period ${ }^{a}$}

\begin{tabular}{l|c|c|c|c}
\hline Cohort $^{\mathbf{b}}$ & $\mathbf{n}$ & Mean & SD & Median \\
\hline Overall & 85,014 & 32.0 & 27.9 & 25.0 \\
\hline NEURO/NOCI & 37,019 & 38.1 & 31.3 & 30.0 \\
\hline NEURO & 2,375 & 25.1 & 23.6 & 18.0 \\
\hline NOCI & 39,496 & 28.4 & 24.6 & 22.0 \\
\hline OA & 6,124 & 20.8 & 18.3 & 16.0 \\
\hline
\end{tabular}

a A visit is counted as 1 unique occurrence per patient per date per provider ID. ${ }^{b}$ All pairwise differences are significant at $P<0.0001$.

NEURO = neuropathic-related neck/back diagnoses; NEURO/NOCI = neuropathic and nociceptive neck/back diagnoses; NOCI=nociceptive neck/back diagnoses; $O A=$ osteoarthritis; $S D=$ standard deviation.

noted in the table. When considering the average total number of different prescribing specialists that patients might have seen during the 2-year period, the overall average was 4.5 specialists (SD 2.6) per patient (Table 6). The NEURO group average was the highest at 4.9 (SD 2.7), followed by the OA group with 4.7 (SD 2.4), the NEURO/NOCI group with 4.4 (SD 2.6), and the NOCI group with 4.2 (SD 2.4). All pairwise tests were statistically significant $(P<0.0001)$.

\section{Medication Use}

Considering all types of medication claims observed among all cohorts, the overall mean prescription claim count per patient for the 2-year observation period was 57.9 claims (SD 56.2; Table 7). Across cohorts, the NEURO/NOCI cohort had the highest mean claim count of 64.6 prescriptions (SD 60.1) and was statistically significantly higher than all other cohorts with the exception of the OA cohort $(P=0.3176)$. Considering only pain-related medications, the overall mean claim count was 8.8 prescriptions (SD 13.0), and the NEURO/NOCI group had the highest mean at 11.0 prescription claims (SD 15.0) during the observation period. All pairwise comparisons of pain medication claim counts between cohorts were statistically significant at $P<0.0001$. Considering adjuvant medication claims, the overall mean prescription claim count was 12.7 prescriptions (SD 15.5) during the period and the NEURO/NOCI mean count was the highest at 13.7 prescriptions (SD 16.5). The nonpain-related prescriptions accounted for the highest volume of claims, with the overall mean during the period of 41.2 claims (SD 42.5). In this category, the OA patients accounted for the highest mean number of prescriptions at 48.0 claims (SD 44.5; $P<0.0001$ for all pairwise comparisons with the OA cohort).

Weak opioids (WHO pain relief ladder rung 2) accounted for the majority of pain medication claims across all cohorts (Figure 2). The percentage of patients who had nonopioids (WHO pain relief ladder rung 1), weak opioids (WHO pain relief ladder rung 2), or strong opioids (WHO pain relief ladder rung 3) available (i.e., filled) were similar across cohorts. A greater percentage of NEURO/NOCI and OA patients had nonopioid availability ( $53.4 \%$ and $55.5 \%$, respectively) than patients in the other cohorts. The percentage of days where medication was available during the observation period was similar across all cohorts with the majority of patients having

\section{TABLE 5 Medical Providers}

Number and percentage of patients per cohort with at least 1 visit to top 10 overall most frequently prescribinga specialty types during the 2 -year observation period.

\begin{tabular}{|c|c|c|c|c|c|}
\hline \multirow[b]{3}{*}{ Specialty ${ }^{b}$} & Overall & NEURO & NEURO/NOCI & NOCI & $\mathrm{OA}$ \\
\hline & $(\mathrm{n}=85,014)$ & $(\mathrm{n}=2,375)$ & $(\mathbf{n}=37,019)$ & $(n=39,496)$ & $(n=6,124)$ \\
\hline & $\%$ & $\%$ & $\%$ & $\%$ & $\%$ \\
\hline General practice/family practice (GP/FP) & 39.8 & 32.2 & 38.9 & 42.1 & 33.1 \\
\hline Internal medicine (IM) & 16.9 & 19.6 & 17.2 & 15.8 & 20.7 \\
\hline Orthopedic surgery (OS) & 6.7 & 8.2 & 6.8 & 5.1 & 16.6 \\
\hline Cardiology (CD) & 4.2 & 5.3 & 4.7 & 3.5 & 5.7 \\
\hline Obstetrics and gynecology (OB) & 3.1 & 3.3 & 2.7 & 3.8 & 1.4 \\
\hline None listed (NL) & 2.5 & 3.2 & 2.2 & 2.8 & 2.2 \\
\hline Other specialty (Oth) & 2.2 & 2.3 & 2.9 & 1.7 & 1.3 \\
\hline Psychiatry (PSY) & 2.1 & 2.4 & 2.4 & 2.1 & 1.1 \\
\hline Nurse practitionera $(\mathrm{NP})$ & 2.1 & 0.6 & 1.8 & 2.7 & 0.6 \\
\hline Rheumatology (RH) & 1.8 & 1.7 & 1.6 & 1.6 & 4.0 \\
\hline Physician's assistant ${ }^{\mathrm{a}}(\mathrm{PA})$ & 1.7 & 0.5 & 1.4 & 2.2 & 0.8 \\
\hline \multicolumn{6}{|c|}{$\begin{array}{l}\text { aPrescribing abilities for controlled substances varies by state. } \\
\text { bPairwise tests showed the following tests that were not significant at P<0.05: NEURO vs. NEURO/NOCI-OS, CD, Oth, PSY, and RH; NEURO vs. NOCI-NL, PSY, RH, } \\
\text { NEURO vs. OA-GP/FP, CD, NP, PA; NEURO/NOCI vs. NOCI-RH; NEURO/NOCI vs. OA-NL; NOCI vs. OA. All are significant at P }<0.05 \text {. } \\
\text { NEURO =neuropathic-related neck/back diagnoses; NEURO/NOCI=neuropathic and nociceptive neck/back diagnoses; NOCI=nociceptive neck/back diagnoses; } \\
\text { OA= osteoarthritis. }\end{array}$} \\
\hline
\end{tabular}




\section{TABLE 6 Different Prescribing Specialists}

Average total number of different prescribing specialty types ${ }^{a}$ per person during the 2-year observation period for all patients. ${ }^{b}$

\begin{tabular}{l|c|c|c|c}
\hline Cohort Group $^{\mathbf{c}}$ & $\mathbf{n}$ & Mean & SD & Median \\
\hline Overall & 85,014 & 4.5 & 2.6 & 4 \\
\hline NEURO & 37,019 & 4.9 & 2.7 & 5 \\
\hline NEURO/NOCI & 2,375 & 4.4 & 2.6 & 4 \\
\hline NOCI & 39,496 & 4.2 & 2.4 & 4 \\
\hline OA & 6,124 & 4.7 & 2.4 & 5 \\
\hline
\end{tabular}

a Subset to specialties who generally prescribe chronic medications (e.g., general practice).

${ }^{b}$ Patients with no prescribing specialty physicians listed on any claims during the observation period were assigned a value of zero.

cAll pairwise differences are significant at $P<0.0001$.

NEURO = neuropathic-related neck/back diagnoses; NEURO/NOCI = neuropathic and nociceptive neck/back diagnoses; NOCI = nociceptive neck/back diagnoses;

$O A=$ osteoarthritis; $S D=$ standard deviation

$0 \%$ to $<30 \%$ of days with pain medication availability. At least 1 prescription for a weak opioid was filled by the majority of patients (85.1\%-88.2\%). However, at least 1 opioid (weak or strong) in the observation year was an analysis inclusion criterion. When strong opioids are considered, at least 1 prescription for a strong opioid was filled by a greater percentage of patients with NEURO/NOCI (42.6\%) or NEURO (39.0\%) diagnoses than patients with NOCI $(29.6 \%)$ or OA $(38.0 \%)$ diagnoses (data not shown on graph). Combination treatment, defined as claims for more than 1 pain medication of any type (i.e., within or between WHO ladder steps), was observed in more than half $(54.5 \%)$ of OA patients, with NEURO/NOCI, NEURO, and NOCI patients following at $53.3 \%, 44.5 \%$, and $38.9 \%$, respectively (data not shown).

Antidepressants, anticonvulsants, muscle relaxants, and steroids were common treatments and were available to approximately $26.2 \%, 11.1 \%$, and $10.6 \%$ of patients, respectively, during the observation period (Figure 3). Patients in the NEURO/NOCI group had greater availability of adjunct medications. This research also identified the subset of medications within these classes that have been described in the literature as being used as adjuvant treatments for pain. Almost all of the drugs within the muscle relaxant and steroid classes are used specifically for pain. There was less certainty with the antidepressant and anticonvulsant classes for pain. Therefore, statistics are shown for both the overall class as well as for the subset typically used for pain relief. The NEURO/NOCI cohort had the greatest percentage of patients using adjunctive medications from each class (antidepressants 41.5\%; anticonvulsants $28.0 \%$; muscle relaxants $46.1 \%$; and steroids $38.1 \%$ ) compared with the other cohorts, with the use of muscle relaxants being most common. A substantial percentage of

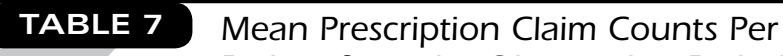
Patient from the Observation Period by Cohort and Pain Category ${ }^{a}$

\begin{tabular}{l|r|r|r|c}
\hline $\begin{array}{l}\text { Prescription } \\
\text { Category/Cohort }\end{array}$ & $\mathbf{n}^{\mathbf{b}}$ & Mean & SD & Median \\
\hline \begin{tabular}{l|r|r} 
All prescriptions \\
\hline Overall
\end{tabular} & 84,983 & 57.9 & 56.2 & 41 \\
\hline NEURO & 2,375 & 58.4 & 54.5 & 42 \\
\hline NEURO/NOCI & 37,010 & 64.6 & 60.1 & 48 \\
\hline NOCI & 39,475 & 50.8 & 51.6 & 35 \\
\hline OA & 6,123 & 63.8 & 55.0 & 49 \\
\hline
\end{tabular}

NEURO/NOCI vs. OA only are not statistically significant, $P=0.3176$; all other pairwise comparisons are significantly different at $P<0.0001$.

Pain-related prescriptions ${ }^{\mathrm{c}}$

\begin{tabular}{l|r|r|r|l}
\hline Overall & 84,679 & 8.8 & 13.0 & 3 \\
\hline NEURO & 2,360 & 8.7 & 13.5 & 4 \\
\hline NEURO/NOCI & 36,895 & 11.0 & 15.0 & 5 \\
\hline NOCI & 39,324 & 6.7 & 10.7 & 3 \\
\hline OA & 6,100 & 9.6 & 11.6 & 5 \\
\hline
\end{tabular}

All pairwise comparisons are statistically significant at $P<0.0001$.

Adjuvant prescriptions $^{\mathrm{d}}$

\begin{tabular}{l|r|r|r|l}
\hline Overall & 58,813 & 12.7 & 15.5 & 7 \\
\hline NEURO & 1,565 & 12.2 & 14.4 & 7 \\
\hline NEURO/NOCI & 28,678 & 13.7 & 16.5 & 7 \\
\hline NOCI & 25,093 & 11.8 & 14.6 & 6 \\
\hline OA & 3,477 & 12.0 & 14.0 & 7 \\
\hline
\end{tabular}

NEURO vs. NOCI $(P=0.3249)$, NEURO vs. OA $(P=0.6621)$, and NOCI vs. OA $(P=0.4952)$ are not statistically significant; all other pairwise comparisons are statistically significant at $P<0.0001$.

Nonpain-related prescriptionse $e^{e}$

\begin{tabular}{l|r|r|r|l}
\hline Overall & 83,236 & 41.2 & 42.5 & 28 \\
\hline NEURO & 2,313 & 42.8 & 42.9 & 29 \\
\hline NEURO/NOCI & 36,306 & 43.9 & 44.2 & 31 \\
\hline NOCI & 38,575 & 37.5 & 40.1 & 25 \\
\hline OA & 6,042 & 48.0 & 44.5 & 36 \\
\hline
\end{tabular}

NEURO vs. NEURO/NOCI is not statistically significant, $P=0.2478$; all other pairwise comparisons are statistically significant at $P<0.0001$.

${ }^{a}$ Claims with missing, zero, or negative days supply or quantity were not included in counts. Claims with identical National Drug Code numbers for the same date and patient were only counted once per date.

bThe category " $n$ " is the number of patients with pharmacy claims in each prescription category.

cPain-related prescriptions include all medications listed for WHO ladder steps 1, 2 , and 3 .

dAdjuvant prescriptions include medications used as adjuvant treatment for pain in the following drug classes: muscle relaxants, antidepressants, steroids, anticonvulsants, antiarrhythmics, and antihypertensives.

${ }^{e}$ Nonpain-related prescriptions include all prescriptions that are not in the painrelated or adjuvant categories.

NEURO = neuropathic-related neck/back diagnoses; NEURO/NOCI = neuropathic and nociceptive neck/back diagnoses; NOCI = nociceptive neck/back diagnoses; $O A=$ osteoarthritis; $S D=$ standard deviation.

patients in all of the cohorts had antidepressant use (range from $32.8 \%$ to $41.5 \%$ ), with approximately half having an antidepressant typically associated with pain relief (tricyclics and serotonin-norepinephrine reuptake inhibitors [SNRI]). 

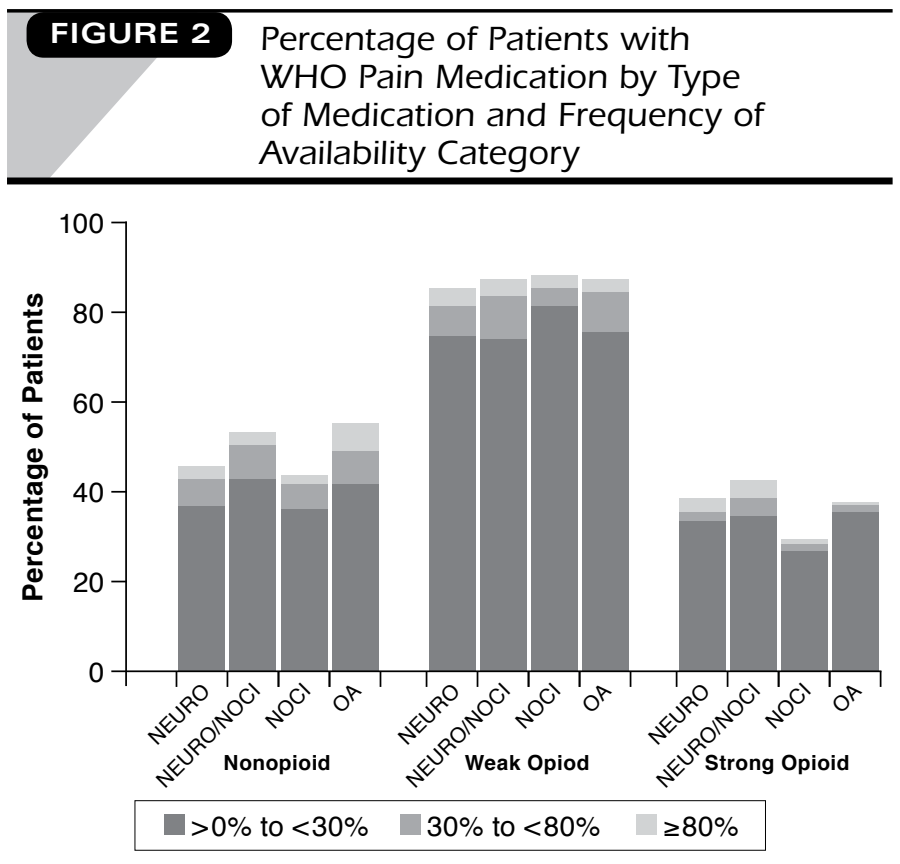

Note: The percentage of days medication available is presented in 3 categories as shaded portions on the bar graph. The difference between the bar height and 100\% represents patients with no use of the product.

NEURO = neuropathic-related neck/back diagnoses; NEURO/NOCI = neuropathic and nociceptive neck/back diagnoses; NOCI=nociceptive neck/back diagnoses; $O A=$ osteoarthritis; $W H O=$ World Health Organization .

Potential Drug Interactions of the Cytochrome P450 Pathway Considering all cohorts, $32.2 \%$ of patients had 10 or more days of overlapping drug availability (of inducers or inhibitors of cytochrome P450 used concomitantly; Table 8). The NEURO/NOCI cohort showed the highest potential for drug interactions, with $38.4 \%$ of patients having 10 or more days of overlapping drug availability. The OA, NEURO, and NOCI cohorts followed with $33.4 \%, 32.3 \%$, and $26.1 \%$, respectively. All pairwise comparisons between cohorts were significantly different at $P<0.0001$ with the exception of NEURO versus $\mathrm{OA}$, which was $P=0.3342$.

\section{Adjuvant Procedures}

According to coding from the Healthcare Common Procedure Coding System (HCPCS), and Current Procedural Terminology (CPT), chiropractic and physical therapies were the most frequently billed coded claims for services among all cohorts except OA patients (Table 9). The NEURO/NOCI and NOCI cohorts used these adjuvant services to a much larger extent than the other cohorts. The most commonly used services among all cohorts included chiropractic therapy, physical therapy, and TENS (bioelectric therapy), but there was variability among services by cohort. Most statistical tests for differences

\begin{tabular}{cl}
\hline FIGURE 3 & $\begin{array}{l}\text { Percentage of Patients with } \\
\text { Adjuvant Medication Use over a } \\
\text { 2-Year Period by Medication }\end{array}$ \\
\hline
\end{tabular}

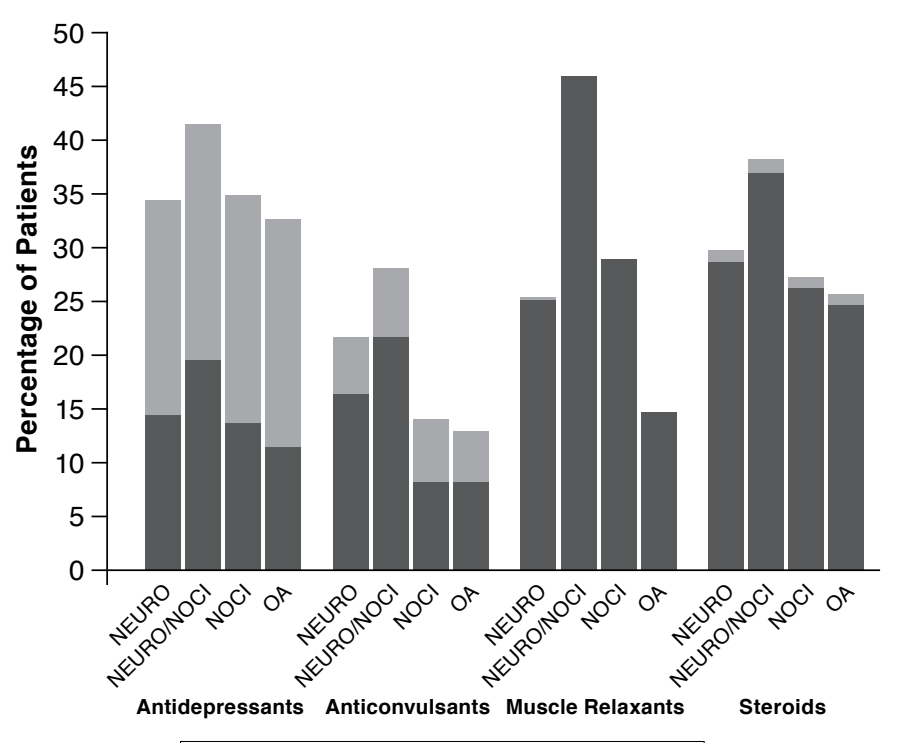

Nonspecific drugs within class

Specific drugs within class that are more typically used for pain

Note: The shaded areas on the bars represent medications within the class that are more typically used for pain (e.g., amitriptyline within the antidepressants) versus those that are not as typically used for pain (e.g., fluoxetine within the antidepressants). NEURO = neuropathic-related neck/back diagnoses; NEURO/NOCI = neuropathic and nociceptive neck/back diagnoses; NOCI = nociceptive neck/back diagnoses; $O A=$ osteoarthritis.

among the cohorts were significant with a few exceptions. Pairwise tests showed the following tests that were not significant at $P<0.05$ : physical therapy for $\mathrm{NOCI}$ versus OA; psychological therapy for NEURO versus NOCI; neuromuscular re-education for NEURO versus NOCI and OA; neuromuscular re-education for NOCI versus OA; spinal cord stimulation for NEURO versus NOCI and NOCI versus OA; and intrathecal pump implant for NOCI versus OA. All other pairwise differences were significant at $P<0.05$.

\section{Discussion}

This assessment provided insights into the challenges physicians face when treating patients presenting with pain. Treatment challenges are complex and encompass patient characteristics (e.g., concomitant illnesses), provider issues (e.g., multiple physician involvement), treatment choices (e.g., types of pain and adjuvants medications used), and treatment consequences (e.g., the potential for drug interactions). 
Complexity of Pain Management Among Patients with Nociceptive or Neuropathic Neck, Back, or Osteoarthritis Diagnoses

TABLE 8 Patients with at Least 1 Potential Drug Interaction

\begin{tabular}{|c|c|c|c|c|c|c|c|c|c|}
\hline \multicolumn{2}{|c|}{ Overall } & \multicolumn{2}{|c|}{ NEURO } & \multicolumn{2}{|c|}{ NEURO/NOCI } & \multicolumn{2}{|c|}{ NOCI } & \multicolumn{2}{|c|}{$\mathrm{OA}$} \\
\hline \multicolumn{2}{|c|}{$\mathrm{n}=85,014$} & \multicolumn{2}{|c|}{$\mathrm{n}=2,375$} & \multicolumn{2}{|c|}{$\mathbf{n}=37,019$} & \multicolumn{2}{|c|}{$\mathbf{n}=39,496$} & \multicolumn{2}{|c|}{$\mathrm{n}=6,124$} \\
\hline $\mathbf{n}$ & $\% a$ & n & $\%$ & $\mathbf{n}$ & $\% \mathrm{a}$ & $\mathbf{n}$ & $\% a$ & $\mathrm{n}$ & $\%^{a}$ \\
\hline 27,358 & 32.2 & 766 & 32.3 & 14,224 & 38.4 & 10,321 & 26.1 & 2,047 & 33.4 \\
\hline
\end{tabular}

${ }^{a}$ Denominator is the number of patients in each cohort. All pairwise comparisons are significantly different at $P<0.0001$ except NEURO vs. OA $(P=0.3342)$.

NEURO = neuropathic-related neck/back diagnoses; NEURO/NOCI = neuropathic and nociceptive neck/back diagnoses; NOCI=nociceptive neck/back diagnoses;

$O A=$ osteoarthritis.

\section{TABLE 9 Number and Percentage of Patients by Most Frequently Billed CPT or HCPCS Categories}

\begin{tabular}{|c|c|c|c|c|c|c|c|c|c|}
\hline \multirow[b]{3}{*}{ WHO Adjuvant Treatment } & \multirow{3}{*}{$\begin{array}{c}\text { CPT/HCPCS } \\
\text { Code for Identification }\end{array}$} & \multirow{2}{*}{\multicolumn{2}{|c|}{$\begin{array}{c}\text { NEURO } \\
(n=2,375)\end{array}$}} & \multirow{2}{*}{\multicolumn{2}{|c|}{\begin{tabular}{|c|} 
NEURO/NOCI \\
$(\mathrm{n}=37,019)$ \\
\end{tabular}}} & \multirow{2}{*}{\multicolumn{2}{|c|}{$\frac{\text { NOCI }}{(n=39,496)}$}} & \multirow{2}{*}{\multicolumn{2}{|c|}{$\frac{\mathrm{OA}}{(\mathrm{n}=6,124)}$}} \\
\hline & & & & & & & & & \\
\hline & & $\mathbf{n}$ & $\%$ a & $\mathbf{n}$ & $\%^{a}$ & $\mathbf{n}$ & $\%$ a & $\mathbf{n}$ & $\% \mathrm{a}$ \\
\hline Chiropractic therapy & 98940-98943, A2000, A9170, X2010, X2020, or X2025 & 687 & 28.9 & 21,776 & 58.8 & 26,521 & 67.1 & 188 & 3.1 \\
\hline Physical therapy & $97001,97002,97110,97140,97530,97150$ & 696 & 29.3 & 17,732 & 47.9 & 13,818 & 35 & 2,102 & 34.3 \\
\hline TENS unit or bioelectric therapy & 97014, 97032, E0720, E0730, G0283, or M0545 & 423 & 17.8 & 15,110 & 40.8 & 12,222 & 30.9 & 710 & 11.6 \\
\hline Ultrasound & 97035 & 230 & 9.7 & 8,317 & 22.5 & 6,303 & 16 & 508 & 8.3 \\
\hline Psychological therapy & $\begin{array}{l}\text { 90801-90899, 95883, 96100-96103, 96117-96120, } \\
\text { G0071-G0094, S9480, W5970, W7962, W7989, } \\
\text { W9076, X0630, X0641, X0646-X0648, X0650, X0651, } \\
\text { X0655, X0660, X0661, X0680, or X0681 }\end{array}$ & 315 & 13.3 & 6,145 & 16.6 & 5,734 & 14.5 & 622 & 10.2 \\
\hline Traction & 97012, E0840, E0849, E0850, E0855, E0856, or E0860 & 121 & 5.1 & 5,976 & 16.1 & 4,109 & 10.4 & 15 & 0.2 \\
\hline Neuromuscular re-education & 97112 & 146 & 6.1 & 4,247 & 11.5 & 2,759 & 7 & 396 & 6.5 \\
\hline Acupuncture/acupressure & $\begin{array}{l}97780,97781,97810,97811,97813,97814, \text { S0008, } \\
\text { X0008, X1420, or X2231 }\end{array}$ & 20 & 0.8 & 1,068 & 2.9 & 844 & 2.1 & 20 & 0.3 \\
\hline Spinal cord stimulation & 63660,63685, or 63688 & 5 & 0.2 & 130 & 0.4 & 11 & 0 & 1 & 0 \\
\hline Intrathecal pump implant & $\begin{array}{l}62350,62351,62360,62361,62362,62367,62368 \text {, or } \\
\text { E0785 }\end{array}$ & 11 & 0.5 & 91 & 0.2 & 24 & 0.1 & 3 & 0 \\
\hline Epidural injection & $\begin{array}{l}64470,64472,64475,64476,64479,64480,64483 \\
64484,62310, \text { or } 62311\end{array}$ & 180 & 7.6 & 9,451 & 25.5 & 747 & 1.9 & 62 & 1 \\
\hline
\end{tabular}

aPairwise tests showed the following tests that were not significant at $P<0.05$ : physical therapy for NOCI vs. OA; psychological therapy for NEURO vs. NOCI; neuromuscular re-education for NEURO vs. NOCI and OA; neuromuscular re-education for NOCI vs. OA; spinal cord stimulation for NEURO vs. NOCI and NOCI vs. OA; and intrathecal pump implant for NOCI vs. OA. All other pairwise differences were significant at $P<0.05$.

$\mathrm{CPT}=$ Current Procedural Terminology; HCPCS = Healthcare Common Procedure Coding System

A large percentage of patients had comorbid conditions. For example, hypertension, a chronic condition frequently requiring lifetime medication treatment, was observed in 36\%-61\% of the cohorts, with the highest percentage observed in the OA group. These results are consistent with those reported by Gore et al., ${ }^{10}$ who used claims data from managed care health plans to assess comorbidities and resource use among OA patients. Rates of comorbid hypertension, hyperlipidemia, and coronary heart disease reported by Gore et al. were 54.4\%, 52.1\%, and $10.6 \%$, respectively. The average age of the Gore et al. analysis population was 56.9 years. In the current analysis, the average age of the OA cohort was 53.6, and hypertension, hyperlipidemia, and coronary heart disease observed in the OA cohort were somewhat higher than those reported by Gore et al., at $61.2 \%, 59.5 \%$, and $11.5 \%$, respectively. The non-OA cohorts in our analysis had comparable cardiovascular comorbidity rates, except that hypertension among the NOCI cohort was lower, at $35.6 \%$. Concomitant rates of depression (12.4\%), anxiety (8.6\%), and sleep disorders (11.9\%) observed by Gore et al. were somewhat lower than reported here $(16.5 \%, 10.7 \%$, 18.9\%). Many patients with a comorbid illness will require chronic medication use. Physicians treating patients presenting with pain need to identify medications used for comorbid illnesses to guard against adverse effects and drug interactions.

This analysis further demonstrated that multiple providers were involved in treating the various pain cohorts. In the current analysis, the mean number of prescribing physicians per patient was 4.5 over a 2-year period. Visiting multiple physicians would not be unexpected behavior when chronic illnesses are involved and likely reflects the need for specialists' care. For example, the mean number of specialists visited by the NEURO group was 4.9 during the 2 -year period. The 
data show the providers seen included GP/FP physicians, IM physicians, orthopedic surgeons, cardiologists, and obstetric gynecologists. Inquiring about medications prescribed by other providers or use of systems that allow physicians to have information from other prescribers would seem prudent.

In terms of treatment choices, weak opioids accounted for most of the pain medication claims used by all cohorts. However, many nonopioids are available without a prescription and may not appear in a paid claims database. The percentage of patients using nonopioids is likely to be an underrepresentation. The mean number of pain-related prescriptions was 8.8 per person over the 2-year period. (The prescription count did not represent consecutive months of treatment but claims that could have occurred at any time during the 2-year period.) This number is more likely indicative of acute pain treatment rather than chronic pain treatment. Chronic pain treatment would have likely resulted in more prescription claims for strong opioids. ${ }^{12,13}$ Strong opioid prescriptions are not refillable and require a new prescription each month; therefore, a higher mean for pain-related prescriptions would be expected for chronic treatment.

Prior research has shown that adequate pain control often requires multiple medications. ${ }^{14-16}$ In this analysis, overlapping or simultaneous prescriptions for multiple pain medications were observed in more than half $(54.5 \%)$ of OA patients, with the NEURO/NOCI, NEURO, and NOCI groups following at $53.3 \%, 44.5 \%$, and $38.9 \%$, respectively. The use of simultaneous medications or perhaps combination therapy might indicate that the primary pain medications were not sufficient as monotherapy for pain relief. A report by Romanò et al. (2012), ${ }^{17}$ discussing the treatment of low back pain, compared monotherapy with combination therapy or placebo for the treatment of low back pain and concluded that monotherapy is often only partially effective treatment and that combining drugs with different mechanisms of action might be a rational approach because of the different mechanisms that cause low back pain. Therefore, combination drug treatment for pain is likely to occur but adds another medication to the patient's overall treatment regimen. Combination therapy may also represent use of multiple opioids. For example, patients could be combining a long-acting opioid with a short-acting opioid for breakthrough pain.

In addition to simultaneous treatment with traditional pain medications, claims for adjuvant treatments including antidepressants, anticonvulsants, muscle relaxants, and steroids were observed in this analysis. The mean number of adjuvant claims was 12.7 per person over the 2 -year period. These results are consistent with the report of Bair and Sanderson $(2011)^{18}$ from a comprehensive literature review of co-analgesics or adjuvant analgesics. The Bair and Sanderson analysis stated that antidepressants (particularly the SNRIs duloxetine and milnacipran), anticonvulsants, skeletal muscle relaxants, topical analgesics, and antispasmodic agents are often used as co-analgesics. According to Bair and Sanderson, the rationale for adjuvant use includes enhancing the effect of opioid analgesics or NSAIDs, providing independent analgesic activity in certain painful conditions, or counteracting the adverse effects of some analgesics. Thus, adjuvant medications are commonly found along with those indicated specifically for pain.

Given the number of prescriptions and concomitant health conditions observed in the pain cohorts, a drug interaction assessment was included to demonstrate the likelihood of interactions among medications. The cytochrome P450 interaction was used because the drugs listed in the claims data could be categorized as inhibitors or inducers of the cytochrome P450 pathway. The results showed that $25.7 \%$ of patients had 10 or more days of overlapping drug availability (of inducers or inhibitors of cytochrome P450 used concomitantly). These types of drug-drug exposures have the potential to cause significant pharmacokinetic interactions. Using a claims database of patients taking opioid analgesics, Summers et al. (2011) ${ }^{19}$ assessed the economic impact of incident drug-drug exposures (DDEs) with the potential to cause pharmacokinetic drug-drug interactions (DDIs). The Summers et al. analysis reported that drug-drug exposures were relatively common among subjects. Furthermore, health care costs 6 months after the DDE were significantly higher in subjects with DDE versus matched subjects without DDE, providing evidence that drug-drug interactions impact health care costs.

\section{Limitations}

As with any claims-based analysis, this analysis may be limited by any coding errors that could have resulted in the misclassification of patients and other variables. Regarding adjunct medications such as antidepressants, there was no information available to verify whether the adjunct medications were used for pain or comorbidities. The claims database does not make it possible to associate prescription claims with diagnoses. Also, the database does not provide a direct link to the provider type who wrote the prescription that appears in the claims data. Several of the analyses presented claim counts. No evaluation of duration of therapy was performed for the adjuvant medications. The DDIs presented in this analysis represented potential interactions. Use of an administrative claims database provides information about drugs that were dispensed; however, there was no way to verify whether the drugs were actually taken simultaneously other than observing overlapping days of supplies. Medications that do not require a prescription are likely to be underrepresented in this analysis. The medications used for this interaction analysis were a selected list of pain-related therapies. Use of a more comprehensive list of all drugs that were actually dispensed would likely detect more potential 
interactions. Furthermore, the DDI analysis is exploratory in nature, and no evaluation of the seriousness of the interactions was performed. This analysis did not include cohorts with nonpain-related diagnoses. No commentary can be provided on how patients with pain-related diagnoses compare with patients without pain-related diagnoses.

\section{Conclusions}

Treatment of patients with pain-related complaints is complex and further complicated by the existence of concomitant illnesses and treatment by multiple specialists. Choosing the appropriate pain treatment involves assessing currently used medications for existing illnesses and deciding on the appropriate types of pain medications. Use of combination and adjuvant prescription medications may be desirable to optimize efficacy. However, potentially serious drug-drug interactions are a consequence of multiple drug use and require thoughtful consideration by those involved in patient care.

\section{Authors}

CHRIS M. KOZMA, PhD, is an Independent Research Consultant, St. Helena Island, South Carolina; DAVID A. PROVENZANO, MD, is President, Pain Diagnostics and Interventional Care, Pittsburgh, Pennsylvania; and TERRA L. SLATON, MS, is an Independent Research Consultant, West Columbia, South Carolina. AARTI A. PATEL, PharmD, MBA, is Associate Director, and CARMELA J. BENSON, MS, is Director, Janssen Scientific Affairs, LLC, Raritan, New Jersey.

AUTHOR CORRESPONDENCE: Chris M. Kozma, PhD, 84 Tomahawk Trail, St. Helena Island, SC 29920. Tel.: 843.838.8064; Fax: 843.838.2328; E-mail: ckozma@c-k-consulting.com.

\section{DISCLOSURES}

Kozma and Slaton received funds through a research agreement with Janssen Scientific Affairs, LLC. Provenzano was a paid consultant for Janssen Global Services, LLC. Patel and Benson are employees of Janssen Scientific Affairs, LLC, and hold stock in Johnson \& Johnson. Support for this project was provided by Janssen Scientific Affairs, LLC.

All authors contributed to the concept and design for this study. Data analysis was done primarily by Slaton, with assistance from Kozma and Benson. All authors contributed to data interpretation, as well as in writing and editing the manuscript.

\section{ACKNOWLEDGMENTS}

Lavonda Miley, $\mathrm{PhD}$, assisted in the preparation and submission of the manuscript.

\section{REFERENCES}

1. Dworkin RH, O'Connor AB, Backonja M, et al. Pharmacologic management of neuropathic pain: evidence-based recommendations. Pain. 2007;132(3):237-51

2. Chou R, Qaseem A, Snow V, et al. Diagnosis and treatment of low back pain: a joint clinical practice guideline from the American College of Physicians and the American Pain Society. Ann Intern Med. 2007;147(7):478-91.

3. Morlion B. Pharmacotherapy of low back pain: targeting nociceptive and neuropathic pain components. Curr Med Res Opin. 2011;27(1):11-33.

4. Smith H, Bruckenthal P. Implications of opioid analgesia for medically complicated patients. Drugs Aging. 2010;27(5):417-33.

5. Orenius T, Koskela T, Koho P, et al. Anxiety and depression are independent predictors of quality of life of patients with chronic musculoskeletal pain. J Health Psychol. 2013;18(2):167-75.

6. Fanciullo GJ, Washington T. Best practices to reduce the risk of drugdrug interactions: opportunities for managed care. Am J Manag Care. 2011;17(Suppl 11):S299-S304.

7. Haanpää ML, Gourlay GK, Kent JL, et al. Treatment considerations for patients with neuropathic pain and other medical comorbidities. Mayo Clin Proc. 2010;85(Suppl 3):S15-S25.

8. Hunt RH, Choquette D, Craig BN, et al. Approach to managing musculoskeletal pain: acetaminophen, cyclooxygenase-2 inhibitors, or traditional NSAIDs? Can Fam Physician. 2007;53(7):1177-84.

9. Centers for Disease Control and Prevention. Percent of US adults 55 and over with chronic conditions. Sept 2009. Available at: http://www.cdc.gov/ nchs/data/health_policy/adult_chronic_conditions.pdf. Accessed August 22, 2013.

10. Gore M, Tai KS, Sadosky A, Leslie D, Stacey, BR. Clinical comorbidities, treatment patterns, and direct medical costs of patients with osteoarthritis in usual care: a retrospective claims database analysis. J Med Econ. 2011;14(4):497-507.

11. American Geriatrics Society Panel on Pharmacological Management of Persistent Pain in Older Persons. Pharmacological management of persistent pain in older persons. J Am Geriatr Soc. 2009;57(8):1331-46.

12. Taylor R, Raffa RB, Pergolizzi JV. Controlled release formulation of oxycodone in patients with moderate to severe chronic osteoarthritis: a critical review of the literature. J Pain Res. 2012;5:77-87.

13. Mailis-Gagnon A, Lakha SF, Ou T, et al. Chronic noncancer pain: characteristics of patients prescribed opioids by community physicians and referred to a tertiary pain clinic. Can Fam Physician. 2011;57(3):e97-e105.

14. Smith HS. Combination opioid analgesics. Pain Physician. 2008;11(2):201-14.

15. Altman RD, Smith HS. Opioid therapy for osteoarthritis and chronic low back pain. Postgrad Med. 2010;122(6):87-97.

16. Gilron I, Bailey JM, Tu D, Holden RR, Jackson AC, Houlden RL. Nortriptyline and gabapentin, alone and in combination for neuropathic pain: a double-blind, randomised controlled crossover trial. Lancet. 2009;374(9697):1252-61

17. Romanò CL, Romanò D, Lacerenza M. Antineuropathic and antinociceptive drugs combination in patients with chronic low back pain: a systematic review. Pain Res Treat. 2012;2012:154781.

18. Bair MJ, Sanderson TR. Coanalgesics for chronic pain therapy: a narrative review. Postgrad Med. 2011;123(6):140-50.

19. Summers KH, Puenpatom RA, Rajan N, Ben-Joseph R, Ohsfeldt R. Economic impact of potential drug-drug interactions in opioid analgesics. J Med Econ. 2011;14(4):390-96. 
APPENDIX A Codes Used for Comorbidity Counts, Patient Counts, and Percentages for Gore et al..$^{10}$ Comorbidities Appearing on Claims Between August 31, 2006, and September 1, 2008

Comorbidity $^{\mathrm{a}}$ ICD-9-CM Diagnosis Code

Mental disorders

Depression

Anxiety

Bipolar disorder

Generalized anxiety disorder

Panic disorder

Post-traumatic stress disorder

Sleep disorders

Insomnia/sleep disorders

Sleep apnea

Cardiovascular disorders

\begin{tabular}{|c|c|}
\hline Hypertension & 401.XX \\
\hline Hyperlipidemia & $272.0,272.1,272.2,272.4$ \\
\hline Coronary heart disease & 410.XX-414.XX \\
\hline Myocardial infarction & 410.XX, 412.XX \\
\hline Congestive heart failure & $428.0 \mathrm{X}$ \\
\hline Peripheral vascular disease & $440.2 X, 440.3 X, 443.9$ \\
\hline Chronic obstructive pulmonary disease & 491.XX, 492.XX, 496.XX \\
\hline Chronic renal failure & 585.XX \\
\hline \multicolumn{2}{|l|}{ Musculoskeletal pain conditions } \\
\hline Rheumatism, excluding the back & 725.XX-728.XX, 729.2X-729.9X \\
\hline Arthritis and other arthropathies & 711.X, 712.X, 713.X, 714.4X, 714.8X, 714.9X, 716.X, 717.X, 718.X, 719.X \\
\hline Back and neck pain, excluding low back pain & $\begin{array}{l}\text { 720.XX, 721.0X, 721.2X, 721.5, 721.6, 721.7, 721.8, 721.90, 722.11, 722.30, 722.31, 722.39, 722.4, } \\
\text { 722.51, 722.6, 722.80, 722.81, 722.82, 722.90, 722.91, 722.92, 723.XX, 724.01, 724.1, 724.5, 724.8, } \\
724.9\end{array}$ \\
\hline Lumbago & 724.2 \\
\hline Low back pain & $721.3 \mathrm{X}, 722.10,722.32,722.52,722.83,722.93,724.02,724.6 \mathrm{X}, 724.7 \mathrm{X}$ \\
\hline Osteoarthritis & 715.X \\
\hline Rheumatoid arthritis & $714.0,714.1,714.2$ \\
\hline \multicolumn{2}{|l|}{ Neuropathic pain conditions } \\
\hline Other polyneuropathies & $\begin{array}{l}\text { 344.6, 353.XX, 354.1, 354.2, 354.3, 354.5, 354.8, 354.9, 355.0, 355.1, 355.2, 355.3, 355.4, 355.5, } \\
355.6,355.79,355.8,357.1,357.3,357.4,357.5,357.6,357.7,357.8,357.9\end{array}$ \\
\hline Back and neck pain with neuropathic involvement & $721.1,721.41,721.42,721.91,722.7 \mathrm{X}, 724.3,724.4$ \\
\hline Trigeminal neuralgia & 350.1 \\
\hline Carpal tunnel syndrome & 354.0 \\
\hline Causalgias & $337.2 X, 354.4,355.71,355.9$ \\
\hline Atypical facial pain & 350.2 \\
\hline Neuritis radiculitis, unspecified & 729.2 \\
\hline Phantom limb pain & 353.6 \\
\hline Autonomic neuropathies & $337.1,337.9$ \\
\hline
\end{tabular}

aThree categories that were not included in the manuscript referenced in the title of this table were included in the results table because of their relevance to neuropathic pain (250.XX), diabetic peripheral neuropathy (250.6X), and postherpetic neuralgia (053.19).

ICD-9-CM = International Classification of Diseases, Ninth Revision, Clinical Modification.

296.2X, 296.3X, 300.4, 311

$300.00,300.5 X, 300.09,300.20,300.22,300.23,300.29,300.3,308.3$

296.4X, 296.5X, 296.6X, 296.7X

300.02

$300.01,300.21$

309.81

$780.5 \mathrm{X}, 307.4 \mathrm{X}$

$780.51,780.53,780.57$

$401 \times x$

$272.0,272.1,272.2,272.4$

$428.0 \mathrm{X}$

$440.2 X, 440.3 X, 443.9$

491.XX, 492.XX, 496.XX

725.XX-728.XX, 729.2X-729.9X

$722.51,722.6,722.80,722.81,722.82,722.90,722.91,722.92,723 . X X, 724.01,724.1,724.5,724.8$,

721.3X, 722.10, 722.32, 722.52, 722.83, 722.93, 724.02, 724.6X, 724.7X

$715 . \mathrm{X}$

344.6, 353.XX, 354.1, 354.2, 354.3, 354.5, 354.8, 354.9, 355.0, 355.1, 355.2, 355.3, 355.4, 355.5 $355.6,355.79,355.8,357.1,357.3,357.4,357.5,357.6,357.7,357.8,357.9$

350.1

354.0

350.2

\begin{tabular}{l|l}
\hline Neuritis radiculitis, unspecified & 729.2 \\
\hline Phantom limb pain & 353.6 \\
\hline
\end{tabular}

\begin{tabular}{l|l}
\hline Neuritis radiculitis, unspecified & 729.2 \\
\hline Phantom limb pain & 353.6 \\
\hline
\end{tabular} 


\section{APPENDIX B World Health Organization (WHO) Category Assignments} for Poly-Pain Analyses (by Ladder Step)

\section{Drug Group}

Analgesics-anti-inflammatory Analgesics-anti-inflammatory Analgesics-anti-inflammatory Analgesics-anti-inflammatory Analgesics-anti-inflammatory Analgesics-anti-inflammatory Analgesics-anti-inflammatory Analgesics-anti-inflammatory Analgesics-anti-inflammatory Analgesics-anti-inflammatory Analgesics-anti-inflammatory Analgesics-anti-inflammatory Analgesics-anti-inflammatory Analgesics-anti-inflammatory Analgesics-anti-inflammatory Analgesics-anti-inflammatory Analgesics-anti-inflammatory Analgesics-anti-inflammatory Analgesics-anti-inflammatory Analgesics-anti-inflammatory Analgesics-anti-inflammatory Analgesics-nonnarcotic

Analgesics-nonnarcotic

Analgesics-nonnarcotic

Analgesics-nonnarcotic

Analgesics-nonnarcotic

Analgesics-nonnarcotic

Analgesics-nonnarcotic

Analgesics-nonnarcotic

Analgesics-narcotic

Analgesics-narcotic

Analgesics-narcotic

Analgesics-narcotic

Analgesics-narcotic

Analgesics-narcotic

Analgesics-narcotic

Analgesics-narcotic

Analgesics-narcotic

Analgesics-narcotic

Analgesics-narcotic

Analgesics-narcotic

Analgesics-narcotic

Analgesics-narcotic

Analgesics-narcotic

Analgesics-narcotic

Analgesics-narcotic

Analgesics-narcotic

Analgesics-opioid

Analgesics-opioid

Analgesics-opioid

Analgesics-opioid

Analgesics-opioid

Analgesics-opioid

Analgesics-opioid

Analgesics-opioid

Analgesics-opioid

Analgesics-opioid

Analgesics-opioid

Analgesics-opioid

Analgesics-opioid

Analgesics-opioid

Analgesics-opioid

Analgesics-opioid
Celecoxib

Generic Name

Diclofenac potassium

Diclofenac potassium

Diclofenac with misoprostol

Etodolac

Fenoprofen calcium

Flurbiprofen

Ibuprofen

Indomethacin

Ketoprofen

Ketorolac tromethamine

Lansoprazole-naproxen

Nabumetone

Naproxen

Naproxen sodium

Sulindac

Valdecoxib

Acetaminophen

Aspirin

Diflunisal

Salsalate

Aspirin-APAP-salicyl-caffeine

Acetaminophen-magnesium-salicylate-phenyltoloxamine-caffeine

Acetaminophen- phenyltoloxamine-caffeine

Acetaminophen-salicylamide-phenyltoloxamine

Acetaminophen-salicylamide-phenyltoloxamine-caffeine

Aspirin buffered (al hydrox-mg hydrox-ca carb)

Aspirin buffered (cal carb-mag carb-mag oxide)

Choline and mag salicylate

Acetaminophen-caffeine-dihydrocod

Pentazocine with APAP

Acetaminophen with codeine

Aspirin with codeine

Aspirin-caffeine-butalbital with codeine

Butalbital-aspirin-caffeine with codeine

Codeine phosphate

Codeine sulfate

Dihydrocodeine compound

Hydrocodone-acetaminophen

Hydrocodone-ibuprofen

Propoxphene compound

Propoxphene HCL

Propoxphene HCL with APAP

Propoxphene napsylate

Propoxphene-N with APAP

Tramadol HCL

Tramadol-acetaminophen

Oxymorphone

Fentanyl

Fentanyl citrate

Hydromorphone HCL

Levorphanol tartrate

Meperidine HCL

Meperidine with promethazine

Methadone HCL

Morphine sulfate

Morphine sulfate beads

Morphine sulfate for continuous microinfusion

Oxycodone HCL

Oxycodone with acetaminophen

Oxycodone with aspirin

Oxycodone-ibuprofen

Oxymorphone HCL
Category for Analysis

WHO-Step 1

WHO-Step 1

WHO-Step 1

WHO-Step 1

WHO-Step 1

WHO-Step 1

WHO-Step 1

WHO-Step 1

WHO-Step 1

WHO-Step 1

WHO-Step 1

WHO-Step 1

WHO-Step 1

WHO-Step 1

WHO-Step 1

WHO-Step 1

WHO-Step 1

WHO-Step 1

WHO-Step 1

WHO-Step 1

WHO-Step 1

WHO-Step 1

WHO-Step 1

WHO-Step 1

WHO-Step 1

WHO-Step 1

WHO-Step 1

WHO-Step 1

WHO-Step 1

WHO-Step 2

WHO-Step 2

WHO-Step 2

WHO-Step 2

WHO-Step 2

WHO-Step 2

WHO-Step 2

WHO-Step 2

WHO-Step 2

WHO-Step 2

WHO-Step 2

WHO-Step 2

WHO-Step 2

WHO-Step 2

WHO-Step 2

WHO-Step 2

WHO-Step 2

WHO-Step 2

WHO-Step 3

WHO-Step 3

WHO-Step 3

WHO-Step 3

WHO-Step 3

WHO-Step 3

WHO-Step 3

WHO-Step 3

WHO-Step 3

WHO-Step 3

WHO-Step 3

WHO-Step 3

WHO-Step 3

WHO-Step 3

WHO-Step 3

WHO-Step 3 